\section{Lithium reduziert Schlaganfallrisiko}

Wissenschaftler prüften in einer retrospektiven Kohortenstudie bei Patienten mit bipolaren Störungen den Zusammenhang einer Lithiumbehandlung mit dem Auftreten von Schlaganfällen. Dazu werteten sie die Daten von einer Million Patienten der National Health Insurance Research Database (NHIRD) in Taiwan aus. Sie fanden heraus, dass das Schlaganfallrisiko unter einer Lithiumtherapie signifikant reduziert wurde. Limitationen sieht Prof. Dr. Michael Bauer, Dresden, darin, dass das Design der Studie keine Rückschlüsse auf einen kausalen Zusammenhang erlaubt.

Psychiatrie Update, Wiesbaden 2016

\section{Fettarme Milch lässt Pickel sprießen}

US-amerikanische Dermatologen haben 120 Teenager, die an Akne litten, sowie 105 Altersgenossen mit reiner Haut befragt, wie viele Milchprodukte sie pro Tag zu sich nehmen, und die Angaben verglichen: Ausschlaggebend war dabei der Fettgehalt. Eine Assoziation mit Akne fand sich nur für "low-fat milk" und "skim milk“, also Milch mit 1\% und 0\% Fettgehalt. Die Teenager, die an Akne litten, tranken im Durchschnitt mit 0,61 Portionen pro Tag deutlich mehr Magermilch als ihre Altersgenossen mit reiner Haut, die es nur auf 0,41 Portionen pro Tag brachten.

LaRosa C L et al. JAAD 2016; online 27. Mai 2016

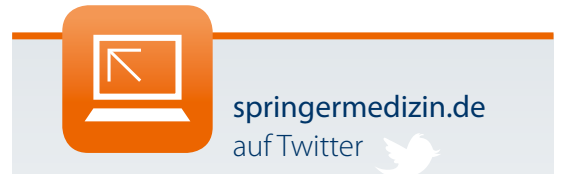

Auch im Sommer heißt es wieder:

Lauschen Sie unserem Zwitschern und werden Sie zum Follower! twitter.com/springermedizin

Onychomykose

\section{Laser kann Therapie von Nagelpilz unterstützen}

Die topische Therapie von Onychomykosen hat mit einigen Schwierigkeiten zu kämpfen. Womöglich hilft die unterstützende Behandlung mit einem Laser, sie zu überwinden.

Die lokale Behandlung von pilzbefallenen Finger- oder Zehennägeln kann auf ein Arsenal wirksamer Substanzen zurückgreifen. Die Wirksamkeit wird jedoch nicht selten eingeschränkt, weil es den Präparaten nicht gelingt, die Nageplatte zu durchdringen. Die systemische Therapie ist eine Alternative, Nebenwirkungen wie etwa toxische Effekte an der Leber setzen ihr freilich Grenzen. Für manche Patienten kommt sie daher nicht infrage. Ein weiteres Problem der Behandlung verpilzter Nägel ist die hohe Rate an Rückfällen.
Dermatologen haben nun untersucht, ob der Einsatz eines Lasers der lokalen Therapie größeren Nachdruck verleihen kann. Beteiligt waren 75 Patienten mit insgesamt 356 befallenen Nägeln. Die Patienten bekamen Terbinafin zur dreimonatigen täglichen lokalen Anwendung verordnet. Zusätzlich wurden die befallenen Nägel dreimal in vierwöchigem Abstand einer fraktionierten Behandlung mit einem $\mathrm{CO}_{2}$-Laser unterzogen. Nach drei Monaten fiel die Pilzprüfung im Kalilaugenpräparat bei 95\% der Patienten negativ aus, in $92 \%$ der Kulturen waren ebenfalls keine Pilze nachweisbar. Die Quoten fielen allerdings mit der Zeit und lagen nach sechs Monaten noch bei $84 \%$ und $80 \%$. (rb)

Bhatta AK et al. J Am Acad Dermatol 2016 (online first)

\section{Frische Spermien}

\section{Kinderwunsch? Täglicher Sex kein Nachteil!}

Oft wird Paaren mit Kinderwunsch in der fruchtbaren Phase Sex höchstens alle zwei Tage empfohlen. Möglicherweise ist der tägliche Koitus aber erfolgreicher. Die Spermienzahl ist dann zwar geringer, dafür haben die Spermien weniger DNA-Schäden.

In einer Studie analysierten Ärzte Samenproben von sieben normozoospermischen Männern mit einem Ejakulationsintervall von ein, zwei, fünf, sieben, neun und elf Tagen. Jeder Mann lieferte also sechs Proben zu den jeweiligen Zeitpunkten. Neben einigen Standardparametern (Spermienzahl und -dichte, Viskosität, Vitalität und Morphologie) bestimmten die Forscher auch die Konzentration reaktiver Sauerstoffspezies im
Samen sowie die DNA-Fragmentierung in den Spermien. Warteten die Männer zwei Tage bis zur nächsten Ejakulation, dann war z.B. das Samenvolumen um 27\% höher als nach einem Tag, elf Tage später betrug der Unterschied 87\%. Die DNA-Fragmentierung stieg mit der Zeit kontinuierlich an und war nach einem Tag deutlich geringer als im Intervall von zwei bis sieben Tagen, allerdings zeigte sich ein klarer Unterschied erst nach fünf Tagen. Nach diesen Ergebnissen, so die Forscher um Dr. Ashok Agarwal, USA, hat täglicher Sex keinen negativen Einfluss auf die Qualität des Spermas, wohingegen lange Intervalle wichtige Qualitätsparameter beeinflussten.

(rb) 